\title{
Nurses' Role in Diabetic Foot Prevent and Care: A Healthcare Challenge
}

\author{
Article by Marrie L Davis \\ Ph.D, Texila American University, Saint Vincent and the Grenadines \\ E-mail: marriedavis63@hotmail.com
}

\begin{abstract}
The diabetic foot is considered one of the most devastating complications of diabetes. Diabetic foot is defined as a foot affected by ulceration. It is associated with neuropathy and or peripheral arterial disease of the lower limb. Health education is a combination of learning experiences designed to help people; by increasing their knowledge and influencing their attitudes to improve well-being. The aims of nursing interventions in diabetic foot careto enhance patients care and services through health promotion, prevention, and patientcentered care. Nurses play vital roles in achieving these goals by providing health care, educating, consulting, being transformational leaders, researching and advocating for patients. However, this action plan focused on the roles of nurses in diabetic foot prevention and care and identified some of the challenges faced. The main goal of the article-to provide health services and to improve the physical, emotional, mental, socio-cultural and spiritual needs of clients.

Education on the basics of foot care, how to perform the physical examination and educating clients on the importance of wearing the right shoes are fundamental areas. Developing educational programs for each client and their families, teaching on the importance of follow-up checks, monitoring of blood glucose at a specified interval, the primary principles of diabetic care and prevention of complications are vital roles of a nurse.

On the other hand, minimizing the risk of the recurrence of the wound is vital. Therefore, by managing contributing systemic factors such as hypertension, hyperlipidemia, obesity, heart conditions or renal insufficiency is crucial. DFU are classified based on the features of the wound and tissues involvement. The study focused on the importance of complying with self-foot care the prevention of complications and the roles of the nurse in the process.

Method: An evaluative study was completed using the nursing process. The monofilament test a method used for the screening process. Educational sessions were conducted and practical demonstrations on the importance of self-foot care. Cases were referred for further management based on the needs identified. Many tables were used to aid in the teaching processes.

Results: All clients visited for follow-up checks were knowledgeable on the importance of compliance with care and ably demonstrated foot examination. $20 \%$ of the clients reported difficulties encountered with complying to care due to socioeconomic challenges. Notably, there were no newly diagnosed cases.

Conclusion: Nurses' roles remained the key factors in managing, caring, educating, advocating and helping clients in modifying their lifestyle practices.
\end{abstract}

Keywords: Diabetic foot, diabetic foot ulcer, education, compliance.

\section{Introduction}

Diabetes is the major cause of blindness, kidney failure, heart attacks, stroke and lower limb amputation (WHO, 2016). Annually, a large sum has allocated for managing noncommunicable diseases and human resources. Healthcare providers play pivotal roles in the prevention and early detection of diabetes and its complications. The role of nurses is to educate in the field of prevention and early detection of any changes in the skin and sensation of the feet. The management of diabetic foot requires close collaboration among health teams. 
Texila International Journal of Nursing

Volume 3, Issue 1, Mar 2017

Compliance to treatment can lead to the increased longevity of clients. The prevention of complications such as eyes, renal, cardiovascular, diabetic foot and impose cost and economic burden on health systems (2006).

The diabetic foot is considered one of the most devastating complications of diabetes. Diabetic foot is defined as a foot affected by ulceration. It is associated with neuropathy and or peripheral arterial disease of the lower limb (Lauterbach, 2010). It is important to note that, care and treatment of diabetic foot are costly worldwide. Therefore, compliance with self and foot care are essential aspects of care. Compliance is the extent to which clients correctly follows medical advice such as medication, dietary plan, and self-care. It also applies to other situations such as medical devices used, self-care, self-directed exercises or therapy sessions (WHO, 2003). Diabetic foot ulcers are results of peripheral nerves damages and arterial diseases (Naves, 2016).

Health education is a combination of learning experiences designed to help people; by increasing their knowledge and influencing their attitudes to improve well-being (WHO, 2017). The aims of nursing interventions in diabetic foot care are to enhance patients care and services through health promotion, prevention, and patient-centered care. Nurses play vital roles in achieving these goals by providing health care, educating, consulting, transformational leadership, researching and advocating for patients. However, this action plan focuses on the roles of nurses in diabetic foot prevention and care. The main goal of the article is to provide health services and to improve the physical, emotional, mental, sociocultural and spiritual needs of the clients. The care provided must be evident-based and render through a holistic approach.

However in St. Vincent and the Grenadines diabetic foot ulcerations (DFU) contributed for most of the amputations done at the main health facility, the Milton Cato Memorial Hospital (MCMH). In 2000, 60.4\% of DFU resulted in amputations, in 2001 and 2002 respectively a total of $65 \%$ increased. Moreover, the average length of hospitalization for a diabetic patient with an amputation average about 52 days and the cost of treatment among to $\$ 300000$ Easter Caribbean dollars. Hence, the importance of nurses' roles to prevent and to improve the quality of care rendered. Also, to combat the many healthcare challenges encountered. Weekly educational sessions and demonstrations were conducted at the Poly Clinic; one of the strategies used to educate diabetic clients on the prevention of complications, compliance with care. Many methods were implemented whereby clients could have a better understanding and acknowledged the importance of complying with care and the possible outcomes. An evaluation of the daily sessions and examination of clients complied. Actual and potential needs were identified and the relevant cases referred for further interventions.

\section{Specific goal}

To enhance patients care and services through: health promotion, prevention, and patientcentered care on managing foot-care.

\section{Methodology}

An evaluative study was completed using the nursing process, assessments of the feet and the monofilament test were methods implemented for examination and screening. Weekly foot examinations were done to assess for foot temperature, toes and soles pressure, and detection for sores, cuts, lacerations, callus and observation for discoloration and skin changes. The monofilament test was applied to determine loss of protective sensation of the feet.

Complete physical assessment on all diabetic clients visited the Poly Clinic for follow-up checks were completed for the period of one month. A brief explanation of the examination process and screening were explained to each diabetic client. Oral consent was obtained. Five diabetic clients were examined and screened daily. Educational sessions were conducted. The significance of complying with self-care was discussed. Practical demonstrations were done to help clients to understand the importance of self-foot care. Cases were referred for further 
management based on findings and actual and potential needs identified. Many approaches were used to aid in the teaching process

\section{Action plan: the roles of the nurse}

Examination and screening-A neurological examination is the first criterion for screening and detection of foot ulcers. Nurses' role in diabetic foot care involves foot examination, wound care and encourage patients and their families on the necessary care and follow-up visits. Screening is a critical part of care. It allows for early detection of diabetic foot problems, identification of those at risk and planning of care to reduce the risk of ulcers.

A foot examination is a routine assessment of temperature, vascular, toe, and sole pressure. A foot care examination includes checks for circulation, nerve damage, skin change, and deformities. Good communication with the client during the process helps to identify other underlying problems.

Devices including a monofilament or tuning fork aided in determining the extent of nerve damage. A monofilament is a thin, flexible thread used. The sense of pressure in various areas of the foot is determined. The tuning folk assessed the sense of vibration in various parts such as the foot and toe joints.

The monofilament testing is done to determine loss of protective sensation of diabetic neuropathic feet for adults and children. It is an inexpensive assessment identifying clients at risk for developing a foot ulcer. Early detection reduces the incidence of diabetic neuropathic ulcers. The Semmes-Weinstein 5.07 monofilament takes 10 grams of force to bend it when it touches on the skin or foot. An inability to detect the degree of force indicates that the client has loss of protective sensation in the foot. A monofilament test should be done yearly as part of an overall assessment for persons diagnosed with diabetes, diabetic foot ulcer, numbness, and tingling, burning or crawling sensation in one or both feet. Diabetic care is holistic and ensuring effective care all other areas of care is vital. Table one indicated the other areas of care necessary for managing diabetic foot ulcer.

\section{Holistic approach to ensure effective care of foot ulcers}

Table 1

\begin{tabular}{|c|l|}
\hline $\begin{array}{l}\text { The past, present and family } \\
\text { history, medications and } \\
\text { allergies }\end{array}$ & $\begin{array}{l}\text { Check for medications that may inhibit } \\
\text { healing such as steroids and } \\
\text { immunosuppressant }\end{array}$ \\
\hline Check for other complications & Neurological, vision, cardiac, renal, vascular \\
\hline$\bullet \quad$ Glycemic control & $\begin{array}{l}\text { Hb (Hemoglobin) A1c }<7.5 \% \text { (depending on } \\
\text { the specific situation of the patient, e.g. } \\
\text { medication, risk of hypoglycemia, body } \\
\text { weight })\end{array}$ \\
\hline$\bullet \quad$ Hypertension control & $<140 / 90 \mathrm{mmHg}$ \\
\hline$\bullet \quad$ Hyperlipidemia control & Cholesterol $<5.2 \mathrm{mmol} / \mathrm{L}(200 \mathrm{mg} / \mathrm{dL})$ \\
\hline
\end{tabular}

Blood sugar control-The primary cause of DFU is due to inadequate control of the blood glucose level (Bowering, 2001). The best indicator of glucose control is HbAlc. It measures the average blood sugar concentration over a 90-d span of the average red blood cell in the peripheral circulation. A high HbAlc level indicated glycosylation of hemoglobin. Greater elevation of blood glucose level has been associated with a higher potential for suppressing inflammatory responses and decreasing host response to infection. Therefore, controlling the blood glucose is vital to prevent foot ulcers.

Nurses' role in education- Educational interventions, critical thinking, screening of highrisk clients and providing health care are interventions implemented to prevent foot ulcers and lower limb amputation. Education on the basics of foot care, how to perform the physical examination and educating clients on the wearing of the right shoes are fundamental areas. Developing educational programs for each client and their families, teaching on the 
Texila International Journal of Nursing

Volume 3, Issue 1, Mar 2017

importance of clinic visits, blood glucose monitoring at specified intervals and the primary principles of diabetic care and prevention of complications are vital roles of a nurse.

\section{Foot assessment and diagnosing of foot ulcer}

Table 2

\begin{tabular}{|c|c|}
\hline Skin assessment & $\begin{array}{ll} & \text { Edema } \\
- & \text { Color } \\
- & \text { Callus } \\
\text { - } & \text { Temperature } \\
\end{array}$ \\
\hline Vascular examination & $\begin{array}{l}\text { Assessed for peripheral arterial disease the following signs may } \\
\text { be present } \\
\text { - Cold feet } \\
\text { - Absent of hair } \\
\text { - Dry, shine and atrophic skin } \\
\text { Check for pulse } \\
\text { - Femoral, popliteal, posterior tibial and dorsalis } \\
\text { - Ankle brachial pressure index measure, the toe pressure } \\
\text { or transcutaneous oxygen can be assessed and due to } \\
\text { arterial calcification a falsely elevated result. }\end{array}$ \\
\hline Neuropathy & $\begin{array}{l}\text { - Sensory loss } \\
\text { - Autonomic-reduce sweating that may result in dry and } \\
\text { cracked skin (a port of entry for bacteria). } \\
\text { Muscular loss-poor reflexes and atrophy of the muscles which } \\
\text { lead to foot deformity. }\end{array}$ \\
\hline $\begin{array}{l}\text { Deformity and } \\
\text { footwear }\end{array}$ & $\begin{array}{l}\text { - Check for deformity-Charcot foot, hammer and claw } \\
\text { toes } \\
\text { - Wear properly fitted shoes }\end{array}$ \\
\hline
\end{tabular}

\section{Ulcer assessment}

Table 3

\begin{tabular}{|c|c|}
\hline Neuropathic pain & $\begin{array}{l}\text { - } \quad \text { Burning. stinging, shooting and } \\
\text { stabbing (non-stimulus dependent) }\end{array}$ \\
\hline Local pain & Deep infection or Charcot joint pain \\
\hline Size & $\begin{array}{l}\text { Length, width, depth, and location, preferably } \\
\text { with clinical photograph }\end{array}$ \\
\hline Wound bed & $\begin{array}{ll}\text { - } & \text { Appearance } \\
\text { - } & \text { Black and necrotic. } \\
\text { - } & \text { Yellow, red, pink } \\
\text { - } & \text { Undermined } \\
\end{array}$ \\
\hline Infection signs & $\begin{array}{l}\text { - Odor } \\
\text { - Be aware that some signs such as } \\
\text { fever and pain } \\
\text { - Increased white blood count may be } \\
\text { absent. } \\
\text { - Evaluate the ulcer for signs of } \\
\text { infection, inflammation, and edema. }\end{array}$ \\
\hline Exudates & $\begin{array}{l}\text { Copious, moderate, minimal and ins some case } \\
\text { none }\end{array}$ \\
\hline Wound edge & $\begin{array}{l}\text { Callus and scales, maceration, erythema, } \\
\text { edema }\end{array}$ \\
\hline
\end{tabular}




\section{Clinical symptoms of neuropathic and ischemic foot ulcers}

Table 4

\begin{tabular}{|c|c|c|}
\hline Clinical signs & Neuropathic & Ischemic \\
\hline Foot deformities & $\begin{array}{l}\text { Clawed toes, possible high arch, } \\
\text { and Charcot deformities }\end{array}$ & $\begin{array}{l}\text { - No obvious deformities. } \\
\text { Possible absent toes or } \\
\text { forefoot from amputation } \\
\text { done before. }\end{array}$ \\
\hline Foot temperature & Warm & Cold or decreased temperature \\
\hline Skin color & Normal or red & $\begin{array}{l}\text { - Pale and bluish } \\
\text { discoloration } \\
\text { - Pronounced redness } \\
\text { when lowered } \\
\text { - Blanching on elevation. }\end{array}$ \\
\hline Skin condition & Dry skin due to decreased sweating & Thin, fragile and dry skin \\
\hline Ulcer site & $\begin{array}{l}\text { Ulcer is seen on the plantar aspect } \\
\text { of the toes and foot }\end{array}$ & $\begin{array}{l}\text { Ulcers present on the distal } \\
\text { and or tip of the toes, heel or } \\
\text { margins of the foot. }\end{array}$ \\
\hline Callus present & $\begin{array}{l}\text { Commonly seen on the weight- } \\
\text { bearing areas and is generally thick. }\end{array}$ & $\begin{array}{l}\text { - Not usually seen. } \\
\text { - If present, seen at the } \\
\text { distal eschar or necrosis }\end{array}$ \\
\hline $\begin{array}{l}\text { Ulcer } \\
\text { characteristics }\end{array}$ & $\begin{array}{l}\text { Painless ulcers, with a "punched } \\
\text { out" appearance. Surrounded by } \\
\text { callus granulation or deep based. }\end{array}$ & $\begin{array}{l}\text { Painful, especially with } \\
\text { necrosis }\end{array}$ \\
\hline Sensation & $\begin{array}{l}\text { Reduced or absent sensation to } \\
\text { touch, vibration, pain, and pressure }\end{array}$ & $\begin{array}{l}\text { - Sensation may be } \\
\text { present. } \\
\text { - Decreased if the ulcer is } \\
\text { associated neuropathy }\end{array}$ \\
\hline Ankle reflexes & Not present & Present \\
\hline Foot pulses & $\begin{array}{l}\text { Present and often bounding with } \\
\text { dilated and prominent veins }\end{array}$ & Absent or markedly reduced \\
\hline
\end{tabular}

\section{The importance of foot care}

Damage to nerves, circulation problems and infections can lead to serious foot problems. Managing diabetes and maintaining a healthy lifestyle helps to keep your feet healthy. Poor foot-care practices account for about $70 \%$ of diabetic patients with lower limb amputations. The risk for lifetime foot ulcer could be as high as 25\% (Abu-Qamar, 2014). Patients with lower limb amputation are faced with many challenges. Therefore, education and preventative activities aid in reducing most of the challenges. Regular foot inspections, medical checks, blood glucose monitoring, regular exercises, healthy eating habits and proper footwear are some preventative methods (Abu- Qamar, 2014).

\section{Foot care procedure}

Foot inspection- check feet and toes, inspect sides, soles, heels and between toes. Use a mirror or asked someone to help if unable inspect. Contact the healthcare team if you discover any sores, redness, cuts, blisters or bruises.

Wash your feet daily in warm water with mild soap make sure the temperature is checked before placing feet into the water. Dry feet and pat between toes well; the moist area is a source of infection. Moisturize skin to prevent dryness; however, do not place lotion between toes.

Daily foot practices include washing of feet but do not use antiseptic solution, hot water bottles, walking barefoot and removing of corn, callus with razor blades or corn remover. 
Texila International Journal of Nursing

Volume 3, Issue 1, Mar 2017

Toenail care- Trim nail after washing your feet. Cut nails straight across and not too short.

Footwear- Choose comfortable well-fitting shoes. Avoid thong sandal, flip flops, pointed and open toes. Wear shoes with adjusted buckles and laces. Inspect the inside of your shoes every day for tear or breakage. Wearing of socks provides an extra layer of protection between the foot and shoes. Wear clean and dry socks. Avoid non-binding pantyhose.

The patient's role- Any laceration must be reported and treated by the healthcare provider. Inspect and check shoes and feet daily. Any changes detected should be reported. Patients should always remove socks and shoes and carry out a daily inspection of the feet.

Nursing role in diabetic foot care at home-Diabetic follow-up is an essential part of the care plan. Home care is necessary for clients with limited vision and other chronic illnesses. A complete assessment should be conducted on every visit. All problems identified should be managed. A foot care guide should be kept at client's home.

\section{Prevention of ulcer formation}

- Daily foot care is essential.

- Daily foot inspection by the client is vital; it could be done by a family member or healthcare provider.

- Wounds or sores should be considered critical and treat with urgent.

- Wear comfortable shoes and inspect them before placing feet.

- Wear supporting and padded sock/stocking.

- Simple injuries to the foot can worsen by home treatments that interfere with the healing process.

- Avoid hot foot soak and the use of an antiseptic solution.

Reinforcing preventative advice and inspecting the client's feet and routine follow-up care. Healthcare provider can help the client to develop and support good foot-care practices.

Preventing other foot problems- Controlling the blood glucose levels reduces blood vessel and nerve damage that can lead to diabetic foot complications. Foot care is an important aspect and following the guidelines in managing diabetes is paramount.

\section{Strategies to reduce the chances of developing foot problems}

DFU is the most costly and devastating complication of DM. It affects about $15 \%$ of diabetic patients during their lifetime. Advanced dressings and offloading modalities remained an essential part of management. Failure of wound healing resulted in lower limb amputation. These factors are associated with gender specifically male diagnosed over 10 years with the disease, advanced age of patients, high Body Mass Index and other comorbidities such as retinopathy, diabetic peripheral neuropathy, peripheral vascular disease, high glycated hemoglobin level (HbA1 C), foot deformity, high plantar pressure, infections and inappropriate foot self-care habits are associated and contributory factors (Waaijman, 2014).

- Complying to self-foot care is the first step to avoid foot ulcer.

- Reduce smoking it worsens vascular conditions by reducing blood circulation to the feet.

- Avoid activity such as walking barefoot; it is a risk for injury.

- Maintain healthy lifestyle practices such as daily physical activities, healthy eating habits; reduce alcohol consumption and comply with medication and follow-up care.

- Control blood pressure

- Lipid management

- Monitor and manage blood glucose levels daily.

\section{Management of DFU}

Treatment is recommended based on the presence and the severity of foot ulcers. Care can be done at home, at the district clinic, and in cases where hospitalization is recommended. 
Case 1 Simple dressing is required, ongoing foot care, monitoring of blood glucose, selfcare management and complying with medication.

Case 2 Closer wound observation and management are needed. The client visits the district clinic daily or three to four times per week. The dressing of the ulcer is done by a healthcare provider.

Case 3 Extensive treatment is needed such as surgical intervention, antibiotics therapy and other treatment to manage the severity of the case.

Medications have a role in the treatment of diabetes; it depends on the complications and the etiologies of diabetic foot ulcers. The approach is holistic. Treatment requires management of systemic and local factors. Diabetic control is critical and achieving resolution and healing of the wound. On the other hand, minimizing the risk of the recurrence of the wound is vital. Therefore, by managing contributing systemic factors such as hypertension, hyperlipidemia, obesity, heart conditions or renal insufficiency is crucial. DFU are classified based on the features of the wound and tissues involvement.

\section{Wagner classification}

\section{Table 5}

\begin{tabular}{|l|l|}
\hline Grade & Ulcer appearance \\
\hline Grade 0 & No open lesions present have deformity or cellulitis \\
\hline Grade 1 & Superficial diabetic ulcer (partial or full thickness) \\
\hline Grade 2 & $\begin{array}{l}\text { Ulcer extended to ligament, tendon, joint capsule, or deep fascia } \\
\text { without abscess or osteomyelitis }\end{array}$ \\
\hline Grade 3 & Deep ulcer with abscess, osteomyelitis, or joint sepsis \\
\hline Grade 4 & Gangrene localized to portion of forefoot or heel \\
\hline Grade 5 & Extensive gangrenous involvement of the entire foot \\
\hline
\end{tabular}

The evaluation and classification of DFU are essential for planning the management of care. The Wagner classification aids in the treatment plan. The classification of wounds is based on the depth as per table 5. Many studies showed decreased in the growth factor concentration in DFU in particular epidermal growth factor. Growth factor shortage impaired wound healing and contributed to chronic non-healing wounds and possible amputation. Epidermal growth factor (EGF) stimulated cell growth proliferation and separation by binding to its receptor. Human EGF a 6045-Daprotein Recombinant human epidermal growth factor sold under the brand name Heberprot-P to treat DFU. Heberprot-P can be injected into wounds (Berlanga, 2013) and used topically (Yang, 2016).

There are several approaches managing DFU. However, in St. Vincent and the Grenadines, an initiative was taken to prevent limb amputations except in extreme cases. The drug Heberprot-P an innovative Cuban product has recombinant human epidermal growth factor for peri-and intra-lesions infiltration is presently used in cases where amputation is considered. The drug accelerates healing of deep and complex ulcers, both ischemic and neuropathic and most importantly reduces diabetic-related amputations. Repeated local infiltration of the drug enhanced healing of chronic wounds. The drug is injected deep into the contours and bottom of the wounds and caused an effective response of tissue growth granulation and wound closure.

Heberprot-P the unique therapy for complicated and recalcitrant chronic wounds associated with high amputation risk. Localized injection in complex diabetic wounds demonstrated favorable risk-benefits ratios by hastening healing, reduced recurrences and attenuated amputation risk (Berlanga, 2013).

\section{The Nurse's roles in the recovery process}

- Guide and educate the client throughout the recovering process.

- Skillfully identify the affected needs and refer case where necessary.

- The care rendered is based on patient-centered goals. 
Texila International Journal of Nursing

Volume 3, Issue 1, Mar 2017

- Educate the client on self-care management and training where necessary.

- Identify the actual and potential problems based on the needs affected.

- Involved the family, the healthcare team, support groups and religion organizations.

- Educate client on the importance of follow-up visits and compliance with care.

- Actively involved all members in the planning of self-care and make sure each task is realistic based on the client's needs.

- Document care and communicate with other healthcare providers for the enhancement of care.

- Evaluate the client's perception and understanding on self-care.

\section{Results}

All clients visited for follow-up checks were knowledgeable on the importance of compliance with care and ably demonstrated foot examination. However, $80 \%$ of the clients were very knowledgeable on the importance of self-foot care modified lifestyle changes and maintained compliance with care. $20 \%$ of the clients reported difficulties with complying to care due to socioeconomic challenges. The clients were referred to social services. Notably, there were no newly diagnosed cases during the examination and screening processes.

\section{Healthcare challenges}

- Length of hospitalization is extended for many patients due to many complications and other related health issues.

- Health care is costly and impacted significantly on a healthcare organization.

- The rising prevalence of the disease, in some countries DM is considered an epidemic.

- The availability of assistive devices, many patients are unable to buy prosthesis due to their poor economic status.

- Some patients are abandoned by their loved ones and the government has to provide suitable accommodation.

\section{Conclusion}

DFU remains the most costly and devastating complication of DM. It affects about $15 \%$ of diabetic patients during their lifetime. Advanced dressings and offloading modalities remain the essential aspect of management. Damage to nerves, circulation problems and infections can lead to serious foot problems. Managing diabetes and maintaining a healthy lifestyle helps to keep your feet healthy. The monofilament testing was done to determine the loss of protective sensation of diabetic neuropathic feet. It was an inexpensive assessment identifying clients at risk for developing a foot ulcer.

Early detection reduced the incidence of diabetic neuropathic ulcers. $20 \%$ of the clients reported difficulties with complying to care due to socioeconomic challenges. The clients were referred to social services.

Health care remained costly and impacted significantly on healthcare organizations due to the rising prevalence of the disease. All clients visited for follow-up checks were knowledgeable on the importance of compliance with care and ably demonstrated foot examination. Notably, there were no newly diagnosed cases during the examination and screening processes. Developing educational programs for each client and their families, teaching on the importance of clinic visits, blood glucose monitoring and the primary principles of diabetic care and prevention of complications are the fundamental roles of a nurse.

\section{References}

[1]. Abu-Qamar, M. (2014). Knowledge and practice of foot self-care among Jordians with diabetes An interview-based survey. Journal of wound care. , Pp. 247-254.

[2]. Berlanga, J. (2013). "Heberprot-P: a novel product for treating advanced diabetic foot ulcer". . MEDICC Review. , PP. 11-15. 
Texila International Journal of Nursing

Volume 3, Issue 1, Mar 2017

[3]. Bowering, C. (2001). Diabetic foot ulcers. Pathophysiology, assessment and therapy. Cam Fam Physician., Pp. 1007-1016.

[4]. Lauterbach, S. K. (2010). Prevalence of diabetic foot syndrome and its risk factors in the UK. J Wound Care. , Pp, 19:333-337.

[5]. Naemi, R. C., \& ingam, N. \&. (2016). Differences in the mechanical characteristics of planter soft tissue between ulcerated and non-ulcerated foot. J Diabetes Complications.

[6]. Naves, C. (2016). The Diabetic Foot: A Historical Overview and Gaps in Current Treatment. ADV Wound Care.

[7]. World Health Organization. (2016). Global report on diabetes. Geneva.: World Health Organization.

[8]. World Health Organization. (2017). Health Education. Geneva: World Health Organization.

[9]. Singh, D. (2006). Diabetic foot: it's time to share the burden. Calicut Med J.

[10]. Tomic-Canic, M. \&. (2004). Gene array technology and pathogenesis of chronic wounds. Am J Surg. , Pp, 67-72.

[11]. Waaijaman, R. (2014). Risk factors for plantar foot ulcer recurrence in neuropathic diabetic patients. Diabetic Care. , Pp. 1697-1705.

[12]. Yang, S. G. (2016). "Efficacy of Topical Recombinant Human Epidermal Growth Factor for Treatment of Diabetic Foot Ulcers. A Systematic Review and Meta-Analysis". The International Journal of lower extremity wounds. , Pp, 120-5. 